\title{
Influence of intrauterine and extrauterine growth on neurodevelopmental outcome of monozygotic twins
}

\author{
R.K. Reolon ${ }^{1}$, N.T. Rotta ${ }^{1}$, M. Agranonik ${ }^{1}$, A.A. Moura da Silva ${ }^{2}$ and M.Z. Goldani ${ }^{1}$ \\ 1Departamento de Pediatria e Puericultura, Faculdade de Medicina, Hospital de Clínicas de Porto Alegre, \\ Universidade Federal do Rio Grande do Sul, Porto Alegre, RS, Brasil \\ 2Departamento de Saúde Pública, Universidade Federal do Maranhão, Sao Luís, MA, Brasil \\ Correspondence to: M.Z. Goldani, Departamento de Pediatria e Puericultura, Faculdade de Medicina, \\ Universidade Federal do Rio Grande do Sul, Rua Ramiro Barcelos, 2400, 90035-003 Porto Alegre, RS, \\ Brasil \\ E-mail: mgoldani@hcpa.ufrgs.br
}

\begin{abstract}
There have been indications that intrauterine and early extrauterine growth can influence childhood mental and motor function. The objective of the present study was to evaluate the influence of intrauterine growth restriction and early extrauterine head growth on the neurodevelopmental outcome of monozygotic twins. Thirty-six monozygous twin pairs were evaluated at the corrected age of 12 to 42 months. Intrauterine growth restriction was quantified using the fetal growth ratio. The effects of birth weight ratio, head circumference at birth and current head circumference on mental and motor outcomes were estimated using mixed-effect linear regression models. Separate estimates of the between (interpair) and within (intrapair) effects of each measure on development were thus obtained. Neurodevelopment was assessed with the Bayley Scales of Infant Development, 2nd edition, by a psychologist blind to the exposure. A standardized neurological examination was performed by a neuropediatrician who was unaware of the exposures under investigation. After adjustment, birth weight ratio and head circumference at birth were not associated with motor or mental outcomes. Current head circumference was associated with mental but not with motor outcomes. Only the intrapair twin effect was significant. An increase of $1 \mathrm{~cm}$ in current head circumference of one twin compared with the other was associated with 3.2 points higher in Mental Developmental Index $(95 \% \mathrm{Cl}=1.06-5.32 ; \mathrm{P}<0.03)$. Thus, no effect of intrauterine growth was found on cognition and only postnatal head growth was associated with cognition. This effect was not shared by the co-twin.
\end{abstract}

Key words: Intrauterine growth restriction; Neurodevelopment; Monozygotic twins; Fetal growth ratio; Head circumference; Neurocognitive development

The present study was funded by both the Foundation on Research and Events of HCPA and the National Council on Research (CNPq).

Received September 20, 2007. Accepted June 9, 2008

\section{Introduction}

Several studies have reported a consistent association between fetal and postnatal growth and neurocognitive development (1-5). Nevertheless, there are difficulties in separating intrauterine and postnatal environmental factors from genetic effects on neurodevelopment outcome due to complex interactions among them (6-8).

Twin studies have been used as a model to distinguish the role of genetic and environmental factors on cognitive function. They have utilized the discordance in growth and development to measure the impact of a hostile intrauterine milieu on neurocognitive development while controlling environmental and genetic variables shared by both cotwins $(9,10)$. Growth restriction in one of the co-twins occurs in approximately 12.5 to $25 \%$ of twin pregnancies $(11,12)$. Compared to the unrestricted twin, the restricted member of the pair may present a higher risk of impaired 
physical and mental development $(13,14)$.

However, these studies presented some methodological limitations, mainly related to interpair analysis. There was a lack of a clear definition of a cut-off point for growth discordance in twins as well as the diversity of growth impairment presentations in twin gestations $(15,16)$. For example, a twin set concordant for birth weight might be severely growth-restricted or vice-versa. Likewise, when comparing two twin sets concordant for birth weight, both pairs might be growth-restricted or non-restricted, or one pair may be restricted and the other non-restricted, depending on the index and cut-off used.

Therefore, the aim of the present study was to determine the influence of intrauterine and early postnatal growth on neurocognitive development of monozygotic twins, using intrapair and interpair differences in some anthropometric measurements collected at birth and at the corrected age of 12 to 42 months.

\section{Subjects and Methods}

This is a retrospective cohort study, with intrapair and interpair comparisons of a sample of monozygous twins. Data were derived from the Brazilian Information System on Livebirths (SINASC), a database of all hospital-based live births in the city of Porto Alegre, Brazil. A total of 601 twin sets were born in Porto Alegre between January 2000 and September 2002. Considering $30 \%$ as the percentage of spontaneous monozygotic twin gestations (17), 180 monozygotic pairs were eligible for the study. Parents were contacted by telephone or letter and attended voluntarily. They were informed that the study comprised clinical evaluation, a standardized neurological examination and assessment of neurocognitive and motor outcomes.

Recruitment was conducted by telephone (43 twin sets) or invitation letter (22 twin pairs). Of these 65 monozygotic twin sets, 13 mothers refused to participate, 4 twin sets did not meet the inclusion criteria due to postnatal death of one or both members and 12 pairs were excluded ( 1 family moved to another city, 7 due to cerebral palsy in one or both members of the pair, 1 pair due to right arm dimorphism in one co-twin and 3 other sets failed to attend a second session to complete the assessment). Thus, 72 children or 36 monozygous twin pairs composed the sample. Zygosity was determined considering chorionicity, amnionicity obtained by ultrasonographic scan according to Scardo et al. (18) and assessment considering the criteria proposed by Bajoria and Kingdom (19) at the time of examination.

The sample size of 36 pairs was calculated considering a difference of 10 points between Mental Development
Index (MDI) means, regarding 15 points for standard deviation (SD) with $80 \%$ of power, using a significance level of $5 \%$.

The following variables were used in the analysis: fetal growth ratio (FGR), newborn gender (female/male), maternal age at delivery in complete years $(\leq 30$ or $>30)$, maternal schooling in complete years $(<8$ or $\geq 8$ ), parity (primiparous or not), maternal smoking during gestation (yes or no), birth head circumference (in $\mathrm{cm}$ ), and current head circumference (in $\mathrm{cm}$ ). Intrauterine growth restriction was determined by the FGR (20), which is a continuous measure obtained by dividing the newborn birth weight by the 50th percentile of the Robertson's twin birth weight distribution for gestational age (21). The lower its value the lower the intrauterine growth. Gestational age was assessed on the basis of neonatal clinical examination using the Ballard method (22) or through a review of ultrasound studies performed before 20 weeks of gestational age (23) or on the basis of clinical examination using the Capurro method (24) in this order of preference. Head circumference was based on the occipital-frontal diameter. All information at birth was obtained from medical records. The term "not known" was added to each variable in the analysis.

The primary dependent variables were the Mental and Psychomotor Development Subscales of the Bayley Scale of Infant Development, 2nd edition (BSID-II) (25) to measure neurodevelopmental outcome at 12 to 42 months of corrected age. The Mental and Motor Scales assess the child's current level of cognitive, language, personal-social, and fine and gross motor development, from which two developmental indices are derived: the MDI and the Psychomotor Development Index (PDI). MDI and PDI were standardized to a mean of 100 , with an SD of 15 , and children whose scores were within this range (100 \pm 1 SD) were considered normal. In all cases, scores were adjusted for gestational age (26). All assessments were blind to the child's birth weight and were performed by a trained psychologist.

Exclusion criteria were malformations, neurosensory impairments (cerebral palsy, deafness and blindness), severe psychomotor retardation and twin-to-twin transfusion syndrome. A standardized neurological examination was performed to determine the presence of neurosensory impairment (27) by a neuropediatrician, who was unaware of the birth weight of the children she evaluated.

The $t$-test was used to compare MDI and PDI between subgroups (by maternal age at delivery, schooling, parity, and smoking). The associations between MDI and PDI with independent variables were performed using mixedeffects regression models with a random intercept for each 
twin pair. 'Robust' standard errors and confidence intervals for estimates have been produced (28). In the first model, MDI figured as the dependent variable and two terms were estimated: a term representing the growth ratio pair means and a term calculating the difference between the individual value and the twin pair mean value of growth ratio (29). This approach allows estimates of the association between intrauterine growth restriction and postnatal head growth on cognitive development adjusted for factors shared within twin pairs (intrapair) while also allowing examination of possible effects of between twin pair (interpair) differences. The second model was created to estimate the associations between PDI and independent variables, using the same guidelines. Both models were adjusted for gestational age and gender. We tested for effect modification in these models using appropriate interaction terms. Analyses were performed using Stata (Stata Software Release 9.0; Statacorp, College Station, TX, USA).

The study was approved by the Ethics Committee of Hospital de Clínicas de Porto Alegre (HCPA). Written informed consent was obtained from parents for the participation in neurodevelopmental assessment. Patients were identified only by study codes.

\section{Results}

A total of 36 monozygotic twin pairs, corresponding to approximately $20 \%$ of monozygotic twins (17) born in the study period, were evaluated. The mean corrected age of the children at the assessment was 29.13 months (range: 12.1041.93). The sample of twins was adequate for gestational age and there was no significant catch up of head circumference during the study period (Table 1). However, $10 \%$ of the newborns weighed less than $1500 \mathrm{~g}$ and nearly a quarter of the sample was growth-restricted at birth (Table 2).

MDI scores were lower for children born from less educated, non-primiparous and smoking mothers (Table 3 ).

In Table 4, there are two estimates of the effects of birth weight ratio, head circumference at birth and current head circumference of Mental and Psychomotor Development Scales. These are estimates of the between (interpair) and within (intrapair) effects of each measure on development. The between twin effects estimate the expected change in the mean PDI
Table 1. Characteristics of 72 monozygotic twins included in the study.

\begin{tabular}{lcc}
\hline Variable & Mean \pm SD & Min-Max \\
\hline Birth head circumference $(\mathrm{cm})$ & $31.78 \pm 2.529$ & $25.0-36.9$ \\
Current head circumference $(\mathrm{cm})$ & $48.44 \pm 1.750$ & $44.1-52.0$ \\
Fetal growth ratio & $0.934 \pm 0.141$ & $0.56-1.25$ \\
Birth weight $(\mathrm{g})$ & $2250 \pm 552.95$ & $840-3295$ \\
Gestational age (weeks) & $35.64 \pm 2.314$ & $30-40$ \\
$|\Delta|$ birth head circumference & $0.29 \pm 1.29$ & $0.0-4.0$ \\
$|\Delta|$ current head circumference & $2.02 \pm 1.356$ & $0.0-4.5$ \\
$|\Delta|$ fetal growth ratio & $0.17 \pm 0.143$ & $0.0-0.66$
\end{tabular}

Data are reported as means \pm SD and as minimum-maximum (Min-Max) interval. $|\Delta|=$ intrapair difference.

Table 2. Neonatal characteristics of 72 monozygotic twins included in the study.

\begin{tabular}{lcc}
\hline Variable & $\mathrm{N}$ & \\
\hline Infants born with less than $1500 \mathrm{~g}$ & 7 & $9.7 \%$ \\
Infants born before 37 weeks of gestation & 42 & $58.3 \%$ \\
Infants born with FGR less than 0.85a & 17 & $23.61 \%$ \\
Birth head circumference & 72 & \\
$\quad$ Median (cm) [p10-p90] & 32.00 [27.50-35.00]
\end{tabular}

Data are reported as number of infants and percent except for birth head circumference, which is reported as median [p10-p90]. in $\mathrm{cm}$ for all twins. FGR = fetal growth ratio. WWith intrauterine growth restriction.

Table 3. Mental Development Index (MDI) and Psychomotor Development Index (PDI) according to maternal age, schooling, parity, and smoking.

\begin{tabular}{|c|c|c|c|c|}
\hline & \multicolumn{2}{|c|}{ MDI } & \multicolumn{2}{|r|}{ PDI } \\
\hline & Mean & $95 \% \mathrm{Cl}$ & Mean & $95 \% \mathrm{Cl}$ \\
\hline \multicolumn{5}{|l|}{ Maternal schooling* } \\
\hline$<8$ years $(30)$ & 85.27 & $79.79-90.74$ & 96.93 & $93.54-100.32$ \\
\hline$\geq 8$ years $(42)$ & 101.67 & $96.33-106.85$ & 99.81 & $96.40-103.22$ \\
\hline \multicolumn{5}{|l|}{ Parity* } \\
\hline Primiparous (36) & 100.67 & $95.55-105.78$ & 97.50 & $93.70-101.30$ \\
\hline Not primiparous (36) & 89.00 & $82.60-95.40$ & 99.72 & $96.61-102.83$ \\
\hline \multicolumn{5}{|l|}{ Maternal smoking* } \\
\hline No (58) & 98.64 & $94.43-102.84$ & 97.79 & $95.03-100.56$ \\
\hline Yes (14) & 79.07 & $68.86-89.28$ & 102.00 & $97.05-106.95$ \\
\hline \multicolumn{5}{|l|}{ Maternal age } \\
\hline$\leq 30$ years $(36)$ & 92.83 & $87.42-98.25$ & 97.75 & $94.17-101.33$ \\
\hline$>30$ years $(36)$ & 96.83 & $90.13-103.53$ & 99.47 & $96.10-102.84$ \\
\hline
\end{tabular}

Data are reported as means and $95 \% \mathrm{Cl}$ (confidence interval at $95 \%$ ).

${ }^{*} \mathrm{P}<0.005$ for comparison of MDI groups ( $t$-test). There were no statistically significant differences between groups for the PDI test. 
or MDI of a pair for a 1 unit increase in each anthropometric measure. The within twin effects estimate the expected difference in PDI or MDI between twins in a pair for a 1 unit difference in each anthropometric measure. Birth weight ratio, head circumference at birth and current head circumference were not associated with motor outcome. There was a significant independent association between intrapair differences in current head circumference and MDI after adjustment (Table 4). There were no statistically significant interactions between the interpair differences in mental outcome and maternal schooling, parity and smoking.

\section{Discussion}

This study demonstrated a significant association between postnatal head growth and MDI due to factors not shared by both co-twins, herein expressed by head circumference differences within twin pairs. Between- and within-pair differences in intrauterine somatic (as measured by the fetal growth ratio) and head growth have been demonstrated not to exert a significant effect on motor outcome.

It has been shown that dizygotic twin sets challenged

Table 4. Mixed-effect multiple linear regression for Mental Development Index (model 1) and Psychomotor Development Index (model 2).

\begin{tabular}{|c|c|c|}
\hline Models & ß & $95 \% \mathrm{Cl}$ \\
\hline \multicolumn{3}{|l|}{ Model 1} \\
\hline FGR within pairs & -3.82 & $-36.23 ; 28.60$ \\
\hline FGR between pairs & 39.32 & $-9.48 ; 88.12$ \\
\hline Birth $\mathrm{HC}$ within pairs $(\mathrm{cm})$ & 1.71 & $-0.45 ; 3.87$ \\
\hline Birth HC between pairs $(\mathrm{cm})$ & -1.74 & $-5.65 ; 2.16$ \\
\hline Current $\mathrm{HC}$ within pairs $(\mathrm{cm})$ & $3.20^{*}$ & $1.06 ; 5.34$ \\
\hline Current $\mathrm{HC}$ between pairs $(\mathrm{cm})$ & 2.28 & $-0.60 ; 5.15$ \\
\hline \multicolumn{3}{|l|}{ Gender } \\
\hline Female & $11.27^{*}$ & $0.78 ; 21.77$ \\
\hline Gestational age (weeks) & 1.19 & $-2.32 ; 4.70$ \\
\hline \multicolumn{3}{|l|}{ Model 2} \\
\hline FGR within pairs & 1.03 & $-34.69 ; 36.74$ \\
\hline FGR between pairs & 15.14 & $-17.28 ; 47.57$ \\
\hline Birth $\mathrm{HC}$ within pairs $(\mathrm{cm})$ & 0.87 & $-0.71 ; 2.46$ \\
\hline Birth HC between pairs $(\mathrm{cm})$ & -0.97 & $-3.61 ; 1.66$ \\
\hline Current $\mathrm{HC}$ within pairs $(\mathrm{cm})$ & 0.14 & $-3.32 ; 3.59$ \\
\hline Current $\mathrm{HC}$ between pairs $(\mathrm{cm})$ & 0.38 & $-1.31 ; 2.07$ \\
\hline \multicolumn{3}{|l|}{ Gender } \\
\hline Female & 2.25 & $-4.60 ; 9.11$ \\
\hline Gestational age (weeks) & 0.47 & $-1.57 ; 2.52$ \\
\hline
\end{tabular}

The data for all 72 twins were used for the linear regression study. Model 2 was adjusted for birth head circumference, gender and gestational age. FGR = fetal growth ratio; $\mathrm{HC}=$ head circumference; $95 \% \mathrm{Cl}=$ confidence interval at $95 \%$. by birth weight dissimilarity above $15 \%$ are probably associated with one growth-restricted infant $(30,31)$ and a higher risk of impaired physical and mental development for the lighter member of the pair $(13,14)$. These findings indicate the effect of individual factors influencing the adaptation in the intrauterine environment. On the other hand, Goyen et al. (9) demonstrated a strong association between cognitive performance and between-pair growth impairment. However, our results did not indicate any influence of intrauterine growth on cognition at 12 to 42 months corrected age, thus not corroborating this report. On the contrary, our findings indicated that only postnatal head growth due to non-shared extrauterine factors might represent a major influence on cognitive development of twins.

The present study provides evidence that the intrauterine factors that affect head circumference development can be modified during an early sensitive postnatal period (32). In our sample, specific adverse effect on cognitive function of infants born from twin gestations was associated with head circumference postnatal growth, indicating that the pattern of head circumference growth during infancy can influence cognition (33). On the other hand, it is not possible to exclude the influence of non-shared factors on systematic environmental experience, such as accidents and illnesses, determining differences in development among co-twins.

No significant influence of birth weight ratio, head circumference at birth and current head circumference on motor outcomes, as measured by the PDI, has been demonstrated in the present study. The fact that motor handicaps were exclusion criteria and that they are more common in twins $(17,34)$ might have reduced the possibility of demonstrating a significant association between intrauterine growth restriction or postnatal head growth and motor outcome.

The finding that higher levels of maternal education were associated with higher MDI scores corroborated studies that demonstrated that more educated mothers might have a positive impact on the cognitive development of infants born from twin gestations $(35,36)$. Evidence $(37,38)$ suggests that maternal smoking during pregnancy may cause harmful effects on cognitive development of the child and an association between maternal smoking during pregnancy and lower cognitive performance was demonstrated in the present study. In contrast to the report of Sørensen and colleagues (3), our results showed an inverse association between maternal parity and cognitive function, i.e., our results showed that first borns have higher MDI scores. The association between higher maternal parity and poorer cognitive outcome corroborated previous findings $(39,40)$, which demonstrated that parity was 
a significant covariate for scores on the mental scale: first borns scored higher than children born later in a family. Further studies may clarify the role of parity in childhood development, i.e., whether growth-restricted infants born later in a family are less stimulated in their mental development. However, the association between MDI and FGR presented the same magnitude in both categories of maternal school education, smoking and parity, suggesting that the effects were not modified by postnatal covariates and presented long-term manifestations.

The present study has some limitations. First, the Bayley Scales of Infant Development II, although employed worldwide for diagnosing developmental delay, might have poor discriminatory power in eliciting minor impairments. Second, due to lack of Brazilian curves of intrauterine growth in twin gestations, Canadian-based curves were used as

\section{References}

1. Jefferis BJ, Power C, Hertzman C. Birth weight, childhood socioeconomic environment, and cognitive development in the 1958 British birth cohort study. BMJ 2002; 325: 305.

2. Walker SP, Thame MM, Chang SM, Bennett F, Forrester TE. Association of growth in utero with cognitive function at age 6-8 years. Early Hum Dev 2007; 83: 355-360.

3. Sorensen HT, Sabroe S, Olsen J, Rothman KJ, Gillman $\mathrm{MW}$, Fischer $\mathrm{P}$. Birth weight and cognitive function in young adult life: historical cohort study. BMJ 1997; 315: 401-403.

4. Matte TD, Bresnahan M, Begg MD, Susser E. Influence of variation in birth weight within normal range and within sibships on IQ at age 7 years: cohort study. BMJ 2001; 323: 310-314.

5. Peterson J, Taylor HG, Minich N, Klein N, Hack M. Subnormal head circumference in very low birth weight children: neonatal correlates and school-age consequences. Early Hum Dev 2006; 82: 325-334.

6. Glascoe FP. Screening for developmental and behavioral problems. Ment Retard Dev Disabil Res Rev 2005; 11: 173179.

7. Sameroff AJ, Seifer R, Barocas R, Zax M, Greenspan S. Intelligence quotient scores of 4-year-old children: socialenvironmental risk factors. Pediatrics 1987; 79: 343-350.

8. Pfeiffer SI, Aylward GP. Outcome for preschoolers of very low birthweight: sociocultural and environmental influences. Percept Mot Skills 1990; 70: 1367-1378.

9. Goyen TA, Veddovi M, Lui K. Developmental outcome of discordant premature twins at 3 years. Early Hum Dev 2003; 73: 27-37.

10. Alin AB. Eight-year follow-up of cognitive development in 33 twin pairs. Acta Genet Med Gemellol 1995; 44: 179-188.

11. Gaziano EP, De Lia JE, Kuhlmann RS. Diamnionic monochorionic twin gestations: an overview. J Matern Fetal Med 2000; 9: 89-96.

12. Quintero RA, Bornick PW, Morales WJ, Allen MH. Selective standards. The use of these data as a standard for intrauterine growth might not accurately represent the Brazilian neonatal population, leading to underestimation of FGR. Third, the small sample size can lead to underestimate the effect of intrauterine variables on the level of cognition at 3 years of age. Fourth, anthropometric measures at birth were obtained from medical records and thus were not standardized. This might have overstated differences in some measures.

The results indicated the complex modulation among genetics and environment. The intrapair differences of postnatal head growth showed that, despite the same genetic background and shared extrauterine environment, higher neurocognitive outcome can be produced due to non-shared environmental factors that promote higher head growth among one of the twins. photocoagulation of communicating vessels in the treatment of monochorionic twins with selective growth retardation. Am J Obstet Gynecol 2001; 185: 689-696.

13. Babson SG, Phillips DS. Growth and development of twins dissimilar in size at birth. N Engl J Med 1973; 289: 937-940.

14. Blickstein I, Lancet M. The growth discordant twin. Obstet Gynecol Surv 1988; 43: 509-515.

15. Raz S, Glogowski-Kawamoto B, Yu AW, Kronenberg ME, Hopkins TL, Lauterbach MD, et al. The effects of perinatal hypoxic risk on developmental outcome in early and middle childhood: a twin study. Neuropsychology 1998; 12: 459467.

16. Boomsma DI, van Beijsterveldt CE, Rietveld MJ, Bartels M, van Baal GC. Genetics mediate relation of birth weight to childhood IQ. BMJ 2001; 323: 1426-1427.

17. Blickstein I. Cerebral palsy in multifoetal pregnancies. Dev Med Child Neurol 2002; 44: 352-355.

18. Scardo JA, Ellings JM, Newman RB. Prospective determination of chorionicity, amnionicity, and zygosity in twin gestations. Am J Obstet Gynecol 1995; 173: 1376-1380.

19. Bajoria R, Kingdom J. The case for routine determination of chorionicity and zygosity in multiple pregnancy. Prenat Diagn 1997; 17: 1207-1225.

20. Kramer MS, Olivier M, McLean FH, Dougherty GE, Willis $\mathrm{DM}$, Usher RH. Determinants of fetal growth and body proportionality. Pediatrics 1990; 86: 18-26.

21. Robertson CM, Svenson LW, Kyle JM. Birth weight by gestational age for Albertan liveborn infants, 1985 through 1998. J Obstet Gynaecol Can 2002; 24: 138-148.

22. Ballard JL, Khoury JC, Wedig K, Wang L, Eilers-Walsman BL, Lipp R. New Ballard Score, expanded to include extremely premature infants. J Pediatr 1991; 119: 417-423.

23. Wood NS, Marlow N, Costeloe K, Gibson AT, Wilkinson AR. Neurologic and developmental disability after extremely preterm birth. EPICure Study Group. N Engl J Med 2000; 
343: $378-384$

24. Capurro H, Konichezky S, Fonseca D, Caldeyro-Barcia R. A simplified method for diagnosis of gestational age in the newborn infant. J Pediatr 1978; 93: 120-122.

25. Bayley N. Bayley Scales of Infant Development. In: Anonymous, The Psychological Corporation. 2nd edn. San Antonio: Hartcourt Brau \& Company; 1993.

26. Ohlweiler L, da Silva AR, Rotta NT. Parachute and lateral propping reactions in preterm children. Arq Neuropsiquiatr 2002; 60: 964-966.

27. Lefévre AB. Exame neurológico da criança. In: Tolosa APM, Canelas HM (Editors), Propedêutica Neurológica. 2nd edn. São Paulo: Sarvier; 1975. p 376-401.

28. Morley R, Moore VM, Dwyer T, Owens JA, Umstad MP, Carlin JB. Association between erythropoietin in cord blood of twins and size at birth: does it relate to gestational factors or to factors during labor or delivery? Pediatr Res 2005; 57: 680-684.

29. Carlin JB, Gurrin LC, Sterne JA, Morley R, Dwyer T. Regression models for twin studies: a critical review. Int $J$ Epidemiol 2005; 34: 1089-1099.

30. Rodis JF, Vintzileos AM, Campbell WA, Nochimson DJ. Intrauterine fetal growth in discordant twin gestations. $J$ Ultrasound Med 1990; 9: 443-448.

31. Gonzalez-Quintero VH, Luke B, O'Sullivan MJ, Misiunas R, Anderson E, Nugent $C$, et al. Antenatal factors associated with significant birth weight discordancy in twin gestations. Am J Obstet Gynecol 2003; 189: 813-817.

32. Drewett R, Wolke D, Asefa M, Kaba M, Tessema F. Malnutrition and mental development: is there a sensitive period? A nested case-control study. J Child Psychol Psychiatry
2001; 42: 181-187.

33. Gale CR, O'Callaghan FJ, Bredow M, Martyn CN, Avon Longitudinal Study of Parents and Children Study Team. The influence of head growth in fetal life, infancy, and childhood on intelligence at the ages of 4 and 8 years. Pediatrics 2006; 118: 1486-1492.

34. Luke B, Keith LG. The contribution of singletons, twins and triplets to low birth weight, infant mortality and handicap in the United States. J Reprod Med 1992; 37: 661-666.

35. Ostfeld BM, Smith RH, Hiatt M, Hegyi T. Maternal behavior toward premature twins: implications for development. Twin Res 2000; 3: 234-241.

36. Pollitt E, Gorman KS, Engle PL, Martorell R, Rivera J. Early supplementary feeding and cognition: effects over two decades. Monogr Soc Res Child Dev 1993; 58: 1-99.

37. Walker A, Rosenberg M, Balaban-Gil K. Neurodevelopmental and neurobehavioral sequelae of selected substances of abuse and psychiatric medications in utero. Child Adolesc Psychiatr Clin N Am 1999; 8: 845-867.

38. Batstra L, Neeleman J, Hadders-Algra M. Can breast feeding modify the adverse effects of smoking during pregnancy on the child's cognitive development? J Epidemiol Community Health 2003; 57: 403-404.

39. Fried PA, Watkinson B, Gray R. Differential effects on cognitive functioning in 13- to 16-year-olds prenatally exposed to cigarettes and marihuana. Neurotoxicol Teratol 2003; 25: 427-436.

40. Largo RH, Molinari L, Comenale PL, Weber M, Duc G. Language development of term and preterm children during the first five years of life. Dev Med Child Neurol 1986; 28 : 333-350. 